\title{
Interview with Paul Cheung
}

\author{
Kirsten West \\ Interview Editor SJIOAS \\ Tel.: +1 443745 4665; E-mail: kwestiaos@gmail.com
}

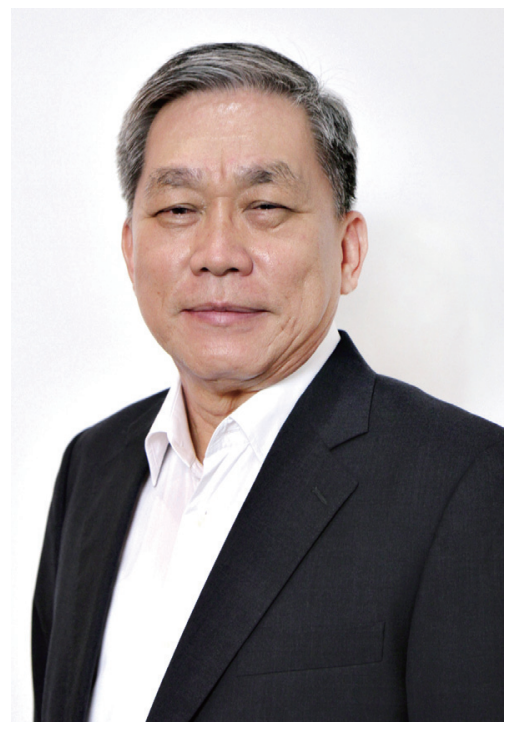

Paul Cheung is Professor of Social Policy and Analytics at the National University of Singapore. He served as Director of the United Nations Statistics Division (UNSD), Department of Economic and Social Affairs at the United Nations Headquarters in New York (2004-2012). He was the Chief Statistician of the Government of Singapore (1991-2004), and the Director of Population Planning in Singapore (1986-1992). Professor Cheung is the recipient of numerous national and professional awards including recognitions from the governments of Singapore, China, Cambodia and Mongolia.

In this interview, Dr Cheung shares about his educational background and professional career. He talks about projects in Singapore and at the UN such as the Initiative in Global Geospatial Management (UNGGIM), his vision for 'the Big Data era,' and data integration. We hear about his involvement with the first ever World Statistics Day, for which he came up with the slogan, "Integrity, Professionalism, and Service to the Nation" to capture the true spirit of official statistics. He also reflects on the future of official statisticians, stating: "At the end of the day, there are many different ways of getting results. We have to stay on top of it. Official statistics cannot afford to be too conservative. We do our work well, but we must allow ourselves room to absorb new methodologies." Finally, he shares his vision for the IAOS. Professor Cheung is a former president of the association (2001-2003).

Interviewers: Let us start by talking about your personal background and your education. We understand you have training in demography as well as statistics. We are both demographers working in government settings as statisticians, so we feel we share some common ground and we are eager to hear about your educational path.

I grew up in Hong Kong. My parents arrived there as refugees. The government of Singapore gave me an educational scholarship and I came to Singapore. At the time, both Hong Kong and Singapore were developing very fast, and there were many opportunities. It was a good time, although it was in the period following the Vietnam War, in the 1970s.

After receiving a bachelor's degree from the University of Singapore, I was again fortunate to earn a scholarship, this time to do graduate studies in the United States. I received a Master's degree in Sociology and Demography and a Master's of Social Work (Social Planning) degree from the University of Hawaii and the East-West Center in Honolulu as well as a Certificate of Population Studies from the University of Hawaii and the East-West Population Institute. 


\section{Interviewer: Is the educational experience different in the United States?}

Yes, it was a different experience. There are differences between being a student in Asia and studying in the United States. In Asia, at the time, there was less technology involved. I was fascinated by computers and everything I could do with them; the automated data libraries, and so on.

Another difference was the level of competition. In Asia, education was very competitive. There were many opportunities, but you had to do well in order to achieve them. The competitive environment has changed, but in countries such as Korea, it is my understanding that children as young as 12-13 years old are still expected to study at least 16 hours a day. It is not that way in the United States.

Interviewer: How did you get interested in Demography?

The field attracted me for many reasons. While I was studying in Hawaii, the Value of Children project got under way in the late 1970 s, early 1980 . I met many scholars involved with that project. Scholars such as Peter Xenos, James Fawcett, James Palmore and Robert Retherford. People such as Griffith Feeney who is now in Boston or New York, or somewhere on the East Coast. The Value of Children project laid down many important principals about why people have children, as well as the cost and benefits of children.

Interviewer: I got my training at the Population Center at the University of North Carolina (UNC)Chapel Hill. I know many of the demographers there would collaborate with researchers at the East-West Center.

Yes. Ron Rindfuss (UNC-Chapel Hill) would come every winter. So would James Sweet from Wisconsin. It was a good time to be at the East-West Center.

There were several other centers where you could do population studies. In addition to UNC, the University of Michigan, the University of Chicago, the University of Texas at Austin come to mind. But there were other places. Studying at the East-West Population Institute was a great experience. All demographers like to come there to do research. It is a famous place and it is the gathering place for demographers.

While I enjoyed my time in Hawaii tremendously and benefitted from all the big names in demography that the East-West Center attracted, I realized that
Hawaii was not the place where I should study for my $\mathrm{PhD}$. There were too many distractions.

I moved to Ann Arbor, Michigan. This came about because Ronald Freedman came to Hawaii. He interviewed me, and invited me to come to the University of Michigan. There, I was able to study demography under Albert Hermalin and William M. Mason, and others at the Population Studies Center. It was a very strong program.

I was also able to study other subjects as well and I ended up with a joint PhD in Social Work (Social Planning) and Sociology (Demography) from the University of Michigan in 1983. I was able to combine my knowledge in social policy and population planning with insight in social architecture, the social services. The design of the $\mathrm{PhD}$ program allowed me to come away with an applied angle.

Interviewers: Interesting! Sociology, Economics or Statistics are the fields usually combined with the study of Demography. Social Work is not the usual choice.

My education was very well rounded. I took econometric courses from scholars such as Jan Kmenta and bio-statistics courses. I got exposure to a variety of disciplines. I was not stuck with a theoretical framework, such as for example the theory of economics, but I was able to learn the methods and the techniques. I could apply information in my own way from different disciplines and utilize different perspectives. Thinking back, it was very useful and it has worked well for me.

Interviewers: This is good transition for our next topic. Tell us about your professional career.

When I returned to Singapore, in the beginning of my career, I taught at the University of Singapore for a couple of years.

Asia was still developing and there was a great interest in matters pertaining to the growth of the population. There was much funding from developed countries for global family planning in developing countries. For example, the USAID invested a lot of money in family planning programs. There was so much money in demography. Singapore did not get as big a share as countries such as Thailand, the Philippines and Indonesia. Demography was at a high point in the late 1970s and the early 1980s. Now, the money has dwindled.

In Singapore, they were looking for demographers. Very soon, I got involved. When I first came back, the population policy was anti-natalist. 'Stop at Two' was 
still the slogan of the day. But when you looked at the numbers you realized that the average family size was actually way below two here and that low fertility was going to be a much bigger problem than overpopulation for Singapore.

Everything I had studied, everything I was taught by Freedman and Hermalin and the other professors at Michigan talked about over-population, I realized that it was not what was going on in Singapore. It did not apply here. I could still use the same theories about why people have babies and why people do not have babies, but I needed to turn the whole argument around. Instead of thinking about population growth, and over-population, I was looking at belowreplacement fertility. An entire different perspective.

Today, in Singapore, the Total Fertility Rate (TFR) is about 1.2 and it has been lower. This year, there has been a slight upswing, perhaps because of 'Dragonbabies.' (According to ancient beliefs, the year of the Dragon is the luckiest of the lunar years. It is usual to observe temporary fertility increases in the Chinese population in Dragon years.)

Below-replacement fertility has become a problem for other countries. The entire region has experienced this. Japan serves as an example. Their TFR dropped below replacement in the middle of the 1970 s, reaching its lowest level (1.4) in 1995, a level it has maintained to this date.

The population policies in Singapore changed in the 1980 s to become pro-natalist. But the strategies have not worked. The question remains, "Why is our fertility so low?" In Europe, they identified the problem earlier, and they too have tried to do something about it without success.

Anyway, after teaching for a couple of years, the government called me up. It was the realization that the country was in a difficult situation. From 1986-1992, I served as the Director for Population Planning. We were the first Asian country to introduce a pro-natalist policy. We looked at the long term projections, looked at numbers long into the future, and we took them seriously. In 1987, we launched a new policy. Instead of telling people to stop at two, we told them to stop at three. We offered a lot of incentives. We reduced the cost of childbearing, and we reduced the cost of childrearing. We tried to address all aspects of having a child. We introduced social policies to support our efforts.

The old social policies were anti-family. We tried to change that to encourage larger families. We tried to be ahead of the curve.
As an aside, let me tell you that we started formulating a pro-natalist population policy in 1986 and as I stated, we launched the first campaign in 1987. The USAID was not too happy with us. And then, right away, in 1988, we immediately saw an upturn in fertility!

I should tell you that 1988 was the year of the Dragon. We were not as successful in the years that followed, but we got off to a good start.

After a few years of working on addressing population policy issues, I got the job as Chief Statistician of Singapore. I took over the office in 1991-there was actually a bit of overlap between the Director of Population Planning job and this position. I served as director until 1992. The population planning job was on a smaller scale than that of chief statistician. Population information, planning, monitoring and evaluation is only a part of a much bigger statistical system. My background in demography served me well. Demographers learn about change and everything I had been taught in the interdisciplinary program at Michigan prepared me for the job as chief statistician.

I saw this new job as offering interesting challenges. I took this job after Singapore had just come off its last census and we were getting ready to make plans for the next census; we were positioning ourselves for the 2000 Census. We looked at the strengths and weaknesses of the Singapore statistical system.

As a small, compact administrative state, we have very good administrative data. The stability and reliability of public databases grew in the 1980s and the 1990 s, and a large amount of administrative data were available by 2000 . It was natural for us to take advantage of this to build a good statistical system and think about a register-based information system. In 2000, Singapore became the first country in Asia to implement a register-based population census. The basic demographic data were obtained from the administrative records. These data were supplemented by a 20 percent sample of enumeration which collected detailed information.

And that was not all. Because we have such a good statistical system, and because we are willing to try all new technology, we also became the first country in the world in 2000 to implement an internet-based selfenumeration methodology in a population census.

It was quite interesting to use the internet. We implemented a multimodal data capture approach. If people did not respond through the internet, then we would try to contact them by phone, and if they did not respond by phone, then ultimately we would go to a personal interview strategy. 
When we first introduced the multimodal response strategy, we knew it was efficient and that we could save a lot of money, but we were not sure if we were introducing methodological biases, so we were very careful with the implementation.

Of course, by 2010 we could build on the experiences gained in our previous census. By then, 44 other countries in the world had also adopted a multimodal methodology, and countries that have not introduced multimodal response options are using new ways to capture data. At the end of the day, I think with the cost concerns and with the populations getting bigger and the statistical offices becoming smaller, efficiency becomes a very important parameter in conducting a population census.

The multimodal approach is still offering the best of both worlds. It gives people some privacy. They can do the response on their own without the government and if not, the field workers come in and do the follow-up. I foresee that the multimodal methodology will continue now that the internet is becoming very popular and getting very successful in countries such as Canada, and in Australia. But, we still do not know enough about the biases in the multimodal methodology, so we need to be very careful.

I am happy to see the development. Since the days when the first UNIVAC machines were introduced in the US, the use of the technology has been steady. WiFi data transmission, wireless technology integrated with the geospatial technology is developing.

I was in Brazil for their 2010 Census. I was in the Amazons, right in the middle of the rainforest, interviewing Indian tribes. After the interview, the data were entered in the PDA (personal digital assistant), and then the information went directly to the headquarters. Can you imagine the kind of efficiency, the kind of speed with which we are able to get the data using wireless technology? We have maps built into the PDAs.

In countries and cities such as Singapore, where everybody is hooked up to a computer, people are highly literate, they value their privacy, but they are responsible citizens. They say, "If you want to get my information, I might as well give it to you." Internet data collection has become so popular, so readily available and so reliable. Internet data collection is very, very nice.

You can see we are moving towards another statistical world, continuing to explore new technologies and employing new technology. Some of this new technology is not only about reengineering. In some sense, the process is always the same. We need to get information from people. But the way we do it needs to be innovative.

By innovations I mean doing things in a completely new way. We are making progress in our efforts with reengineering the census in Singapore. We are getting census taking to be a more efficient operation.

One final point about the census. I was the chair of the International Technical Committee 1 for the 2014 Myanmar Census (Burma). It has been 30 years since Myanmar conducted a census. The country used to be under British rule, so they have a history of census taking. But 30 years of not taking a census puts you far behind in terms of offering any new technology, so they had been using population estimates, and they were estimating that the population in 2014 would be about 60 million or over. After the census was taken, we found out that it was only around 52 million. There had been a gross overestimation of the population.

Myanmar and many other countries such as Iraq and Afghanistan are countries with special circumstances. They cannot move as fast as modern technology will allow. They have to go back to the basic methods. How do you count people when you do not have computers and you do not have stable environments? So my point is, that on the one hand we are talking about innovations, reengineering, high tech, and so on, but on the other hand, at the other end of the spectrum, we are still talking about doing the census in the traditional basic way, where you go in and get it done. It was quite an interesting contrast for me to be a consultant to that project.

Interviewers: Before moving on to the next topic, may we ask you one more question relating to the 2000 Singapore Census? Do you recall the response rates by mode?

In the 2000 Singapore Census, the internet response rate was around 20 percent, about 60 percent by telephone, and the rest by personal interviews. It reduces the cost of census taking tremendously to only have to do about 20 percent by personal visit.

I believe the US could be successful in using the internet if it was fully implemented and done systematically. It is working in Canada. It works in Korea. In the 2010 Census, Statistics Korea took advantage of the internet. I think they achieved almost 60 percent of the responses through the internet option. Can you imagine the cost savings!

\footnotetext{
${ }^{1}$ The board is made up of international experts assembled by the United Nations Population Fund (UNFPA).
} 
In the old days, Australia used a method of leaving a questionnaire with the respondent and then coming back to pick it up. It was so inefficient. For every census, they had to hire so many field workers. They would pump millions of dollars into the economy. They are rethinking their census taking process, including internet options. In countries where people have access to the internet, where they are literate, it is the way to do the census. It is so efficient and much better than using the mail or using interviewers to drop off questionnaires.

The use of the internet ties in with the register-based census. We have a good idea of the household structure.

Interviewers: Singapore did not get to keep you, because in 2004 you went to the United Nations. From 2004 to 2012 you served as the Director of the United Nations Statistics Division (UNSD) Department of Economic and Social Affairs at the United Nations Headquarters in New York. Tell us about your time at the UN.

I was in Singapore Statistics for 14 years and I feel I accomplished a lot. During my tenure, we rebuilt Singapore's national information system and led Singapore to be the first country to conduct a register-based population census. As the Chief Statistician, I got to know the system and the statistical production process and I was able to interact with my counterparts in many countries. It was a good preparation for the UN role.

During my time in Singapore, I served as the President of the International Association of Official Statistics (IAOS), Chairman of the Governing Board, Statistical Institute for Asia and the Pacific (UN-SIAP), and as the Chair of the UNESCAP Committee on Statistics. These experiences got me interested in international official statistics.

The position at the UN had been held before me by Hermann Habermann. He was there from 1994-2002 and then Willem de Vries was acting from 2002-2004 while they were trying to recruit me. I started in 2004.

Interviewers: From the UN, Dr. Habermann went to the US Census Bureau where he became the Deputy Director and Chief Operating Officer from 2002-2006. So, the way it worked out, the UN's loss of a director, became a gain for the US Census Bureau.

Yes, it is my understanding that Dr. Habermann was instrumental in the construction of a new Census Bureau building in Suitland, Maryland.
Hermann Haberman and I came to the job with different backgrounds and experiences. He is more of a pure statistician. He has a PhD in statistics - agricultural statistics - very theoretical. As I have told you, my educational background is more in applied statistics and I came in with a work experience in a national statistical office which gave me a broad international base. Also, I came from a developed Asian country. We approached global statistics in slightly different ways.

Interviewers: While at the UN, you facilitated the development of the global statistical system. You had the responsibility of implementing the UN mandates on geospatial information, cartography, and geographic names. In 2011, your initiative of establishing an inter-governmental platform to address issues on Global Geospatial Information Management was endorsed by the UN Economic and Social Council. Tell us about your UN projects.

When I came to the UN, I was met with a lot of goodwill and I started with the vision that I would build up the global statistical system. Foremost, I would build the UN Statistical Commission to become the apex of the global statistical system. When I started, only about 70 countries (mostly developed countries) had chief statisticians taking part in the Commission. The members would include chief statisticians such as Ivan Fellegi from Canada, Tim Holt from the UK and Katherine Wallman from the US. Now, we have about 140 countries attending every year, and it is no longer just the developed countries talking. It is a 'United Nations.'

Before I came, there were very few side meetings. Now there are many side events (close to 60). The UNSC session has become a truly global event with so many countries and agencies coming. It used to be a 34 days event. Now, the event lasts one or two weeks because there are so many side meetings. Many different groups besides the UN organize the side events. The IMF (International Monetary Fund), EUROSTAT and other similar organizations show up. There are many different global statistical topics to discuss involving the population, economics, and so on.

Now New York is the 'statistical hub.' This is the place where you do business. This is where the lead statisticians come together for two weeks every year. That is the key to the success of the global statistical system. We have a focal point for discussing global statistics.

In 2010, on October 20, we went on to organize the first ever World Statistics Day. It was very successful. 
Some 140 countries organized events in their countries, often involving their heads of states.

There were also events in the US. To celebrate the globe's first World Statistics Day, Katherine Wallman and others participated in a Capitol Hill policy briefing on the importance of the nation's statistical system. She read a message from President Barack Obama praising the value of statistical data. It was the first time ever that a head of state issued a declaration like that.

The caption on our World Statistics Day web site read: 'Celebrating the many achievements of official statistics.' The activities on that day were intended to raise awareness of official statistics premised on the core values of integrity, professionalism and service to the nation. I believe these three themes capture the true spirit of official statistics, our aspirations, what we do, why we do it and how we do it. On this particular day, we celebrate and we raise awareness of the many achievements of official statistics.

The event in 2010 went well and the countries agreed to have a World Statistics Day every five years. We decided not to do it annually. If we do it too frequently, there is a concern that we will dilute the message. I believe the UN is in the process of organizing something for 2015, the second World Statistics Day.

Having organized the international statistical community, I realized that the next step was to look at all the new sources of data available to us. The world is an ever-changing place. As the director, I had to respond to changes and seek out new possibilities. For us, as official statisticians, if we just focus on the things that we do, and we do them very well, then we become too narrow. We have the CPI and all the other traditional official statistics. We have the surveys, we have the censuses. All the traditional data sources. We have to be responsive to new fields of information. We have to look at location information as well, to Big Data information, to 'unstructured data.'

The US is having a significant input on these issues. You may recall the memo written by Lawrence (Larry) Summers and others that got it all started and the recent White House Executive Office report on Big Data. There is an ongoing public debate in the US about these issues.

I believe that government statisticians are not looking broadly enough. As official statisticians, we are not providing a service to our governments if we do not look at new data, if we do not incorporate location information and utilize Big Data. It is not the official statistical policy to do so yet, but it is good policy to do so.
Actually, I have had a chance to talk to your boss about this issue, Undersecretary Mark Dorms in the Department of Commerce. In July 2014, the Department of Commerce appointed the first ever Chief Data Officer (CDO). This is an interesting turn of events. Because theoretically, sitting in the Department of Commerce, the chief can pull together data on labor conditions, health information and so on from many different sources. It is much more efficient when all the data are linked together. The chief can play a much larger role by linking data to policy. This is a new experiment. Much is happening indeed in the world of statistics now.

But I get ahead of myself. Let me answer your initial question about UN projects and talk to you about the UN Initiative in Global Geospatial Management (UNGGIM).

While all this was happening, organizing the international statistical community, I also realized that we needed a way to organize the world with regard to geospatial information. We needed to have a mechanism internationally to talk about how to manage geospatial information and their integration with other sources of information. Who is going to organize and coordinate?

The UN was established in 1945. Since 1947, the UN Statistical Commission has guided us in our work in setting the standards and in charting the path of the global statistical system. Following that tradition, in 2011, the UN charted the UN-GGIM to organize and coordinate all the geo-information, organize mapping and so on. Without coordination, you have geospatial information on one hand and statistics on the other. It is not useful unless they are linked together. We will just have two different silos.

I feel I started a good thing with this project. In the beginning, only a few people were involved. It evolved. Now it is much bigger. We are riding on the curve of the technology, of the people. It is a new group of people. In February of this year, the UN General Assembly adopted the first resolution on GGIM: 'A Global Geodetic Reference Frame for Sustainable Development' to improve accuracy of location information. This is a major achievement.

I urged the statistical community to seize the moment. A global forum took place, in 2014, at the fourth UN-GGIM session. The forum was on the Integration of Statistical and Geospatial Information. It aimed to continue the global network of consultation and communication.

The discussion was very useful and now, we can see that the countries are responding to this call for 'infor- 
mation integration.' There are meetings being held on setting up global standards, on ways to geo-code information, on methods for doing the integration. I think if we can integrate spatial data and official statistics, then we will have taken our statistics to a new level.

This development is no surprise. In the US, at the U.S. Census Bureau, you have for example Tim Trainor and his staff producing two million maps every year, slicing and dicing the census data every which way and linking it with location data. The private sector also does so much with census data and maps. It has become a new industry because we have an open data policy in the US. This is also happening in other countries. We have Mexico (the National Institute of Statistics and Geography) and Brazil (the Brazilian Institute of Geography and Statistics) onboard. They are producing statistics and geo-spatial data under one roof.

We are looking at a two-pronged trend, here. The question is how do we integrate all this information and how do we keep this going?

Interviewer: Yes, integrating the location information with the statistical information on population or economic information, health information and so on, is something we are striving to do, in the US, at the federal government level. For example, we have developed FIPS (Five-digit Federal Information Processing Standards) codes to help us link data geographically. It is mind-boggling to think of doing this globally.

The Obama administration's open data policy, Sheryl Sandberg of Google and Facebook, Larry Summers and others opened an entire new industry in the US. Over the years, the language has changed in the White House memoranda on this topic. The first memorandum on open data policy focused on ideology, democracy, empowerment, and citizen rights and so on and so forth. In the second memorandum on open data policy, which was issued in 2013, the language changed. The second memo focused on the benefits. It identified opportunities for big data to grow the economy, to improve health and education, to help us become more energy efficient.

In the 2014 report, they are now talking about data fusion. One can no longer be relying on one stream of information such as the census or a general household survey. We need to combine many data sources. That gives us more insight. It is very powerful.

I am pushing for data fusion now and for looking into how we can move this agenda further. I am pushing the global statistical community into developing
Big Data. There really is a lot of interest in this topic. I gave a talk about Big Data to the World Bank in 2012. It was webcast all over the world. I have given this topic a lot of thought for years. We need to work on integration of information from different data sources, official statistics, geo-spatial information and 'unstructured' Big Data. 'Unstructured' means that the data varies in form, in shape, in type.

We also need to be ready to analyze this information, to understand the patterns that we see in these new data sets. New methodologies are evolving. Big Data itself can generate its own benchmark, but that benchmark needs to be put into context. At the end of the day, for a lot of important attributes you still need official statistics to serve as the benchmark, as a reference point to understand the information.

We have all the statistical methodologies that we are familiar with - we know how to calculate the population mean, the sampling mean, how to control the sample to the population, we can compute all the inferential statistics, and so forth, but for Big Data you cannot do all this. Having the official statistics as a benchmark is a necessity for validation purposes.

Statisticians need to work together on this. Many countries are starting to incorporate Big Data into their official statistics, either as a component or as standalone statistics. We need to move this further.

Interviewers: We want to make sure, we cover all aspects of your career in this interview. Let us turn to your return to Singapore. You have now come full circle and you are back to being a university professor. Since 2012, you have been teaching at the National University of Singapore. What are you teaching? What do you believe are some of the challenges that will face future statistician? How are you teaching your students to become the statisticians of tomorrow?

I teach two courses. The first course is on social policy. How statistics informs policy and how information becomes policy. The second course is on Big Data, official statistics and public policy. This is about how government utilizes information. It is an interesting course. I have people from all over the world come in to take that course. I more or less elaborate on some of the points I have made over the years within an educational framework.

The problem for statisticians nowadays is to keep up with the flow of information. We have a lot of challenges working as traditional statisticians and demographers. There is a new kind of statisticians coming of 
age. They call their field 'data analytics.' Many have a background in business, mostly in operational management. Some are trained in the field of engineering, perhaps computer science. They come in, they look at the data, they screen the patterns and then they come up with some kind of conclusion.

There is a big group out there now using data from mobile phones to replicate census results. They can do that. That begs the question, if you can do that, do you actually need a population census?

It is an interesting argument. There are pros and cons. The census has a political foundation and I do not think the governments will ever get rid of it, but the methodology can change. There are so many other ways of coming up with the numbers, or a set of numbers. Data are being used to become socially aware, to predict and track population movement.

The field of data analytics is making a very important contribution. We have to realize that. As statisticians, we are a little bit stuck on the old program. We are stuck on the traditional surveys. Census taking goes back how many centuries? The 'granddaddy-designs', collecting data using interviewers, etc., are very rigorous; they are well tested and work reasonably well, but they leave big holes in catching information. Analytics builds on the methodologies that we know, but they are applied to new approaches to capture the data, to detect patterns and structures.

How do we deal with this? This is a bit of a question for academics. But statisticians working with official statistics have to understand these dynamics. We have our surveys, but the survey data comes out two years later. The information is needed now. Dealing with the flow of information requires new platforms.

The university programs that teach statistics now, in any university, need to come up with some way of offering an integrated program that includes for example, demography, Big Data analytics, biostatistics, econometrics, etc. The point is to create a program that draws on many professions.

Interviewers: We are now going to have your prophecy in print. Ten years from now when these programs are established, we will know that you were the one advocating for this and that the idea should be attributed to you!

We know that the 'pure statisticians,' the 'pure demographers' are out there and are still very important. But it would be very difficult to start out making a living today as such. Dealing with the flow of information requires new ways of looking at the data.
Take demography, the discipline of population studies, as an example. We always use the component methodology to check on population growth (the new population equals the old population plus births, deaths and net international movements). The method has a good track record. We understand the dynamics. We are familiar with this method. But it requires a lot of information. There are other ways.

Take stochastic models. Pure stochastic models have 'no grounding' on the ground. But now, we can use mobile phone data combined with stochastic models to get the results. That gives us 'grounded results' right away.

At the end of the day, there are many different ways of getting results. We have to stay on top of it. Official statistics cannot afford to be too conservative. We do our work well, but we must allow ourselves room to absorb new methodologies.

For example, we still do the census, but we have reengineered the process. The same goes for the entire discipline. We need to reengineer the process.

Interviewers: You are offering us so much to think about. Let us complete our conversation by talking a little bit about the International Association of Official Statistics (IAOS). You served as President of the IAOS from 2001 to 2003. From your perspective how has the organization evolved over the years? What role do you see for the IAOS in the future?

The IAOS and the UNSD complement each other. They both deal with official statistics, but one is smaller and less formal than the other. In the IAOS, when we develop a program, we can invite people to come. We have a lot of flexibility. In the UNSD, the process is more formal. The IAOS is a place where people are free to talk, to bring up new methodologies, to challenge the status quo, to come up with new ideas.

The mission for the IAOS is to bring in new topics. We have to be open and challenge the profession to come up with new ideas. For example, in 2002, we organized an IAOS conference in London, near the Westminster Abbey. Len Cook was the director of the Office of National Statistics (ONS) at the time. It was a big to-do. We organized it around the topic 'Official Statistics and the New Economy.' The conference generated a lot of discussion and a lot of new ideas related to the Systems of National Accounts (SNAs). We forced ourselves to address a new trend. The conference resulted in the conclusion that the existing method of measuring the SNAs had to be revised. We needed a new way 
to compile a fully integrated set of accounts to measure a nation's production, income and wealth. For the next five years, we worked on this and came up with a new SNA. In 2008, a new SNA was produced. When people use the measure today, they should trace it back to that IAOS conference.

Since then I think the IAOS has lost its intellectual vigour. We are meandering, we are overwhelmed by the UNSD. The UNSD can do so much more because they have more money. The donor money enables them to develop activities for large groups of statisticians to attend. The IAOS must focus on new issues, focus on keeping a good professional assessment of reality, provide a professional direction for the future. That is the true calling of the IAOS.

Interviewers: We are coming to the end of this interview - unfortunately...

As my concluding statement then I would like to end by reminding the readers of the Journal of the three principles "Integrity, professionalism and service to the nation." Having been in this field for so long, I think these words sum up what official statistics, what the profession, is all about. I hope, they will continue to be promoted by the IAOS.

IAOS must play two roles. It must challenge the profession to move forward, to come up with new ideas, but at the same time it must remind the professionals in the discipline of the core values of integrity and professionalism as we serve the nation. Focusing on integrity, focusing on professionalism and on service to the nation - these are good ideas.

We have had this discussion at our meetings during ISI gatherings. For example, we talked about this in Hong Kong. But at the time we got sidetracked by the crisis in Greece, the crisis in Argentina. We did not get to do any work focusing on these three issues.

IAOS is at a turning point. We are not making an impact on the professionalism side. We need to do more in these areas. On the core values of professional ethics side, we are also not doing much. These two sides must remain the strongest prongs of the organization as a way to counter the influence of official channels.

Interviewers: We thank you so very much for your time, for getting up early on a Monday morning and starting off your busy day in Singapore by talking to us.

The telephone interview of Dr. Cheung took place in January 2015. Kirsten West and Katherine Condon conducted the interview.

Kirsten West (now retired) worked as a demographer at the U.S. Census Bureau. Her area of expertise was population estimation and census coverage measurement. She has worked on the 1990 Post-Enumeration Survey, the 1991 Evaluation Survey, the 1991 Evaluation Survey, and the 2000 and 2010 Demographic Analysis operation. She holds a PhD from the University of North Carolina at Chapel Hill.

Katherine Condon is a demographer/sociologist at U.S. Citizenship and Immigration Services (USCIS) Office of Policy and Strategy. She holds a PhD from Florida International University (Miami, FL) in Sociology and Anthropology and has a Masters (and is ABD) from University of Pennsylvania (Philadelphia, PA) in Demography. Prior to joining USCIS, she worked at the U.S. Census Bureau in the Population Division's Population Estimates and Projection Area's Administrative Records and Methodological Research Branch, as well as in the Decennial Programs Area. 